\title{
Avaliação do estudante - aspectos gerais
}

\section{Student assessment - general aspects}

\author{
Maria Paula Panúncio-Pinto', Luiz Ernesto de Almeida Troncon²
}

\begin{abstract}
RESUMO
A avaliação do estudante nas profissões da saúde desempenha um papel importante na sua formação. Avaliar significa obter informações que vão ajudar nas tomada de decisões. Assim, é necessário que o planejamento e a execução da avaliação considerem as suas múltiplas finalidades, entre as quais merece destaque a de reforçar o aprendizado (avaliação formativa). O foco da avaliação do estudante deve se concentrar não somente no conhecimento adquirido (habilidades cognitivas), mas também nos domínios psicomotor e afetivo. O planejamento de uma avaliação eficaz no cumprimento de suas funções, leva em conta os objetivos educacionais específicos de cada etapa da formação, de acordo com perfil final desejado de habilidades e competências. A escolha dos métodos deve se pautar no que se deseja avaliar e também nas finalidades da avaliação, considerando validade, fidedignidade, viabilidade, aceitabilidade, impacto educacional e efeito catalítico, como atributos indispensáveis a uma boa avaliação. No cenário atual brasileiro das profissões da saúde ainda prevalece o foco exclusivo na avaliação cognitiva, privilegiando a função somativa, em detrimento da formativa, referenciada por disciplinas e desconsiderando os aspectos afetivos e psicomotores de relevância à sua formação geral. A transformação deste cenário demanda considerar e privilegiar as perspectivas do estudante e capacitar os professores para a avaliação integrativa e transformadora, o que constitui atribuição das escolas, dos sistemas de saúde e dos órgãos reguladores da educação e das profissões.
\end{abstract}

Palavras-chave: avaliação educacional; estudante; educação nas profissões da saúde.

\section{Conceitos básicos}

Em termos gerais, "avaliação" é um substantivo feminino que se refere ao ato de avaliar. Para sua definição, dicionários trazem os verbetes "avaliação" (ato de avaliar, valor determinado por peritos, apreciação; estima) e "avaliar" (determinar o valor de; compreender, apreciar, prezar, conhecer o valor). Quem avalia o faz em relação a "alguma coisa" ou a "alguém” (um verbo transitivo). ${ }^{1}$
1. Professora Doutora do Departamento de Neurociências e Ciências do Comportamento; Faculdade de Medicina de Ribeirão Preto, Universidade de São Paulo

2. Professor Titular do Departamento de Clínica Médica, Faculdade de Medicina de Ribeirão Preto, Universidade de São Paulo
Correspondência:

Prof. Dr. Luiz Ernesto de Almeida Troncon Divisão de Gastroenterologia / Departamento de Clínica Médica Hospital das Clínicas da FMRP- Campus da USP

Av. Bandeirantes, 3900

CEP: 14048-900 - Ribeirão Preto / SP

Artigo recebido em 22/05/2014 Aprovado para publicação em 19/06/2014 
Na perpectiva da educação, "avaliação" é um termo que abrange qualquer atividade em que a evidência de aprendizagem é recolhida de forma planejada e sistemática, sendo utilizada para emitir um juízo sobre a aprendizagem. É importante, porém, considerar que este juízo deve servir a alguma finalidade e, no contexto educacional, as várias finalidades possíveis deveriam ter o propósito do incremento do aprendizado e do aperfeiçoamento do processo educacional.

\section{Finalidades da avaliação}

Neste sentido, se a finalidade da avaliação é ajudar nas decisões sobre a melhor forma de dinamizar a aprendizagem, a avaliação é formativa em sua função. Caso o objetivo consista em sintetizar a aprendizagem até o momento da avaliação, para classificar, certificar ou registrar o progresso, então a avaliação é somativa em sua função. ${ }^{2}$ É importante notar que os atributos "formativa" ou "somativa" referemse á função da avaliação e não ao método.

A avaliação somativa, por sua vez, é informativa em sua função, e as informações que ela fornece sobre a classificação do estudante, feita por meio de conceitos ou notas, subsidiam a tomada de decisão sobre a progressão do estudante, em termos de aprovação ou reprovação, a partir do produto de conhecimentos, habilidades e atitudes, apresentado em situações planejadas. Em geral a avaliação somativa envolve testes formais (provas de múltipla escolha, dissertativas, orais), mas sua função informativa também pode ser obtida progressivamente, através de outras estratégias (trabalhos, seminários, exercícios). ${ }^{3}$

A avaliação formativa ou "avaliação para aprendizagem", como também é referida na literatura, tem função diagnóstica. Ela é planejada, mas pode ser proposta sempre que necessário. $\mathrm{O}$ foco é a aprendizagem do estudante, e esta função só pode ser atingida se o estudante for informado sobre seus objetivos e critérios. A avaliação diagnóstica permite reconhecer a aprendizagem adquirida e não só contribui para desenvolver no estudante a capacidade de autoavaliação, como também promove motivação. ${ }^{4}$

Em sua função formativa, a avaliação identifica pontos fortes e fracos, de acordo com o diagnóstico que ela fornece sobre a aprendizagem, permitindo assim que mudanças sejam propostas, ao longo do processo pedagógico. Fornece informações sobre a eficácia educacional, a partir do reconhecimento do processo de apropriação dos saberes pelos estudantes, os diferentes caminhos percorridos, a regulação da aprendizagem. Desta forma, permite reverter ou alterar rotas mal sucedidas no percurso pedagógico. ${ }^{3}$

É importante destacar que as diferentes funções da avaliação podem conviver desde que garantida coerência com o momento e os objetivos de sua proposição no processo educacional. Igualmente, as estratégias para a avaliação somativa e formativa podem ser as mesmas (avaliação escrita, oral, trabalhos, seminários, resenhas, exercícios, portfólio).

Uma estratégia de avaliação pode ser tradicional em sua forma, e o caráter inovador derivar da atitude do professor, do seu compromisso em tornar o estudante sujeito, ativo em seu processo de aprendizagem. Nesse ponto, o feedback, que pode ser considerado como a espinha dorsal da avaliação formativa, assume papel central. O resultado da avaliação precisa ser compartilhado com o estudante, não apenas sua tradução em conceito/nota. Prover feedback é fundamental para conferir sentido a avaliação, em qualquer de suas funções, independente da estratégia utilizada.

Além de acessar inúmeros aspectos da aprendizagem do estudante, a avaliação deve permitir olhar para o ensino, para o professor e sua prática pedagógica, implicando em reflexão sobre a práxis. ${ }^{5}$

\section{O que avaliar: definindo o foco da avaliação}

A definição da forma e do conteúdo da avaliação requer que algumas perguntas sejam respondidas: "Que profissional eu quero formar?"; "Quais as habilidades e competências este profissional deve desenvolver ou adquirir?"; "Em quais etapas do curso?".

O planejamento de uma avaliação eficaz no cumprimento de suas funções informativa e diagnóstica, vai então depender do reconhecimento dos objetivos educacionais específicos de cada etapa da formação, de acordo com perfil final desejado (habilidades e competências), que, usualmente encontra-se bem definido no Projeto Político Pedagógico-PPP* do curso. Além disso, é necessário considerar os múl-

\footnotetext{
* O PPP representa a proposta da instituição universitária em relação ás suas funções. Em geral ele contém os fundamentos teóricos, filosóficos e políticos da formação profissional proposta; os objetivos da formação, o perfil final desejado para o profissional (habilidades e competências), as estratégias para se atingir esse perfil; a estrutura e o encadeamento de componentes curriculares.
} 
tiplos domínios da aprendizagem significativa em termos de conhecimento, habilidades e atitudes, ou seja: aprendizagem em nível cognitivo, psicomotor e afetivo. Esses três domínios educativos se sobrepõem no processo de aprendizagem e foram identificados por Bloom e colaboradores, no final de década de 1940, em um trabalho clássico que foi publicado com o título "A taxonomia dos objetivos educacionais". Este trabalho, que ficou conhecido como "Taxonomia de Bloom" apresenta os domínios cognitivo e afetivo como capazes de estruturar a capacidade cognitiva em seis níveis de complexidade crescente ${ }^{6}$ (Figura 1).

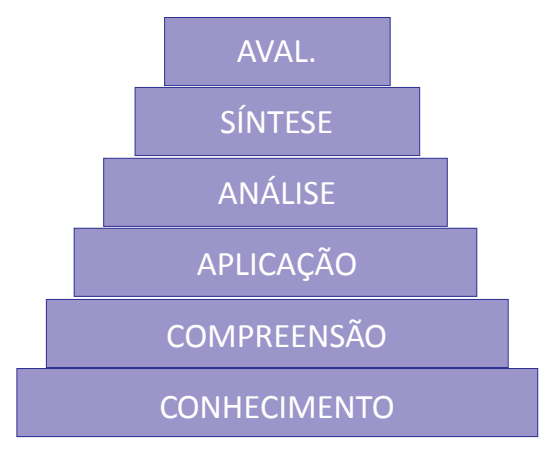

Figura 1: Taxonomia de Bloom ${ }^{6}$ - Primeira Versão.

Em 2001 foi publicada uma revisão da Taxonomia de Bloom com a combinação do tipo de conhecimento a ser adquirido (dimensão do conhecimento) e o processo cognitivo utilizado (dimensão dos processos cognitivos). ${ }^{7}$ A taxonomia de Bloom revisada gerou uma estrutura que auxilia na definição clara dos objetivos de aprendizagem. A nova es- trutura apresenta dois eixos, o do conhecimento, apresentado em quatro dimensões - factual (vocabulário técnico, fontes confiáveis de informação); conceitual (teorias, modelos, princípios e generalizações); procedimental (habilidades específicas, técnicas e métodos) e metacognitivo (conhecimentos sobre processos cognitivos e autoconhecimento) e o dos processos cognitivos, propriamente ditos, apresentado em seis operações - relembrar (definir, memorizar, listar, reproduzir), entender (classificar, descrever, discutir, explicar, identificar, reconhecer), aplicar (escolher, demonstrar, ilustrar, interpretar, resolver), analisar (comparar, criticar, discriminar, distuinguir, examinar), avaliar (justificar uma decisão, argumentar, selecionar, julgar) e criar (construir, desenvolver, formular, desenhar, escrever). Uma mesma atividade ou "tarefa" em avaliação pode ser marcada em mais de uma célula (Tabela 1). Em outras palavras, cada uma das dimensões do conhecimento (factual, conceitual, procedimental e metacognitivo) pode ser avaliada a partir de uma ou mais operações cognitivas.

A “Taxonomia de Bloom" descreve, também, outros dois domínios, além do cognitivo, o das habilidades psicomotoras e o das afetivas. As habilidades psicomotoras dizem respeito ao "fazer", ou seja, tudo o que demanda efetuação neuromuscular. Constituem exemplos deste tipo de habilidade o manusear um objeto ou equipamento, ou o que é envolvido nas ações do exame físico, como o palpar. As habilidades afetivas dizem respeito ao "pensar" ou ao "sentir" frente um objeto, pessoa ou situação. Compreende as opiniões, juízos, valores e atitudes que o estudante adquire em relação às coisas ao vivenciar os processos educacionais.

Tabela 1: Taxonomia de Bloom Revisada

\begin{tabular}{|c|c|c|c|c|c|c|}
\hline \multirow[b]{3}{*}{ Dimensão do Conhecimento } & \multicolumn{6}{|c|}{ Dimensão dos Processos Cognitivos } \\
\hline & A & B & $\mathrm{C}$ & $\mathrm{D}$ & $\mathrm{E}$ & $\mathrm{F}$ \\
\hline & Relembrar & Entender & Aplicar & Analisar & Avaliar & Criar \\
\hline \multicolumn{7}{|l|}{ 1. Conhecimento Factual } \\
\hline 2. Conhecimento Conceitual & & $\mathrm{B} 2$ & $\mathrm{C} 2$ & & & \\
\hline 3. Conhecimento Procedimental & & & & & E3 & F3 \\
\hline 4. Conhecimento Metacognitivo & & & & D4 & & \\
\hline
\end{tabular}


A "Taxonomia de Bloom" oferece um bom modelo para a definição de competências profissionais. Em termos gerais, "competência" pode ser definida como a capacidade de executar uma ação ou exercer uma função no nível desejado de qualidade. No campo profissional, especialmente na área da saúde, uma competência poderia ser conceituada como o domínio, em nível adequado de qualidade, de diferentes habilidades, de naturezas diversas (cognitivas, psicomotoras e afetivas), necessário para executar ações visando a solução de problemas. Por exemplo, "dar um ponto" em um corte na pele, pode ser entendido como uma habilidade psicomotora, enquanto realizar uma sutura seria uma competência, pois exige não só a habilidade psicomotora de "dar um ponto", mas conhecimentos sobre as linhas de tensão da pele e sobre as propriedades do instrumental, como também habilidades afetivas relativas às características da pessoa cuja pele é suturada e com quem o profissional que executa a ação deve necessariamente interagir.

Embora criticada por teóricos e pensadores das ciências humanas e sociais, a taxonomia de Bloom fornece elementos importantes para estruturar a avaliação da aprendizagem nos cursos de graduação da área da saúde. A principal crítica refere-se ao risco de se lançar um olhar insular ao processo de ensinoaprendizagem. Ao utilizar a proposta de Bloom sobre os domínios da aprendizagem significativa, tornan- do-a um guia para estruturar a avaliação, corre-se o risco de valorizar o produto da aprendizagem, o desempenho visível, aceitando sem crítica a "apologia da competência". Isso reduziria a avaliação a um processo de controle de resultados, através de técnicas de medição. ${ }^{8}$ Contudo, aceitar a complexidade do processo ensino-aprendizagem implica em abrir mão da dicotomia do "ou" é bom "ou" é ruim e aceitar o "e", ou seja: acolher o que o modelo tem de interessante para a avaliação da aprendizagem em cursos da saúde e, ao mesmo tempo, aceitar as críticas à "pasteurização" de dirigir o foco para o produto, criando assim possibilidades de diminuir os erros de uma pedagogia meramente centrada em resultados.

\section{Como avaliar: a escolha dos méto- dos nas profissões da saúde}

A escolha dos métodos a serem empregados na avaliação do estudante deve se pautar no critério do melhor ajuste à natureza das habilidades e competências cujo domínio se quer conhecer. Esta tarefa é facilitada por alguns modelos conceituais, como a " $\mathrm{Pi}$ râmide de Miller" (Figura 2), proposta pelo grande estudioso da educação médica norte-americano George Miller ${ }^{9}$, no início dos anos 1990, que parece particularmente interessante para a escolha de métodos de avaliação aplicados ao ensino nas profissões da saúde.

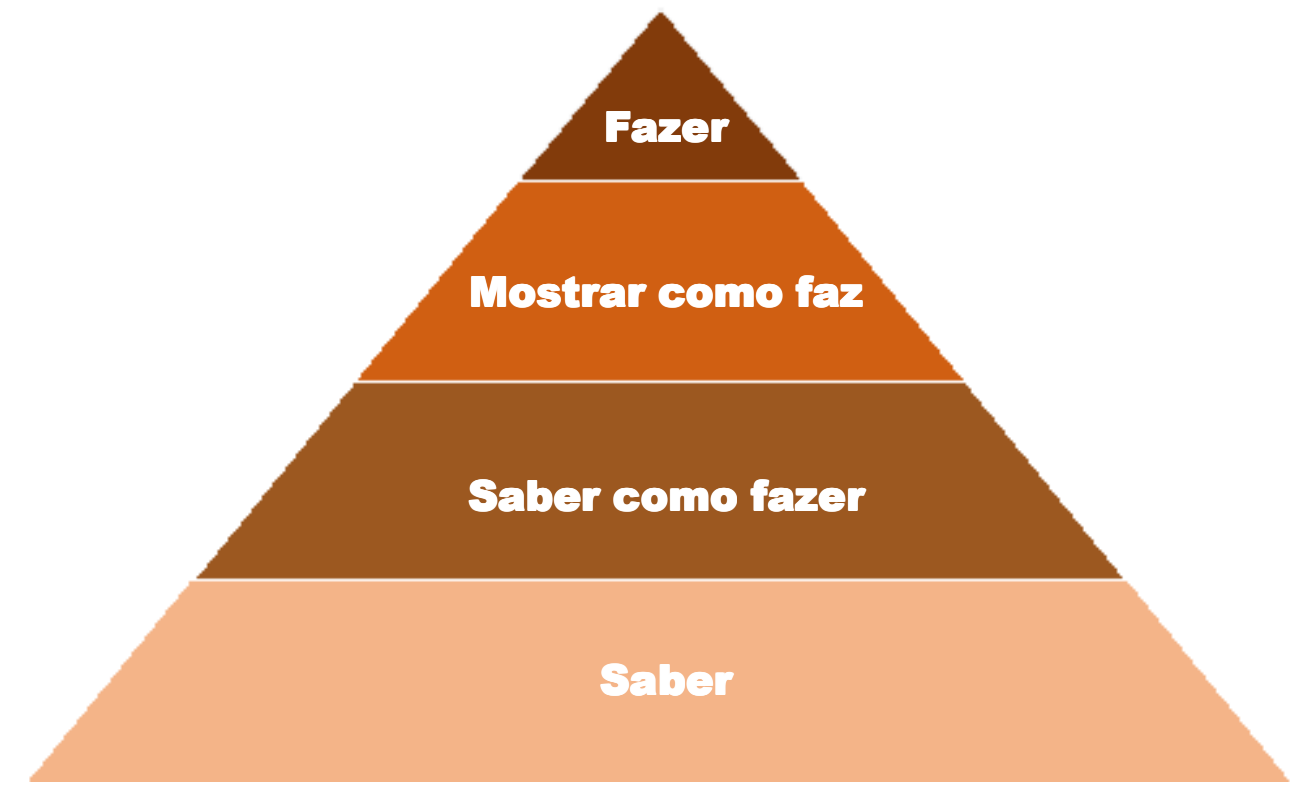

Figura 2. A "Pirâmide de Miller", modelo conceitual que ilustra as bases cognitivas ("saber" e "saber como fazer") da prática profissional ("fazer") e a necessidade da avaliação de habilidades e competências práticas ("mostrar como faż'), especialmente interessante nas áreas clínicas ${ }^{9}$. 
Neste modelo, se pressupõe que a prática profissional, o "fazer", se assenta no conhecimento do "saber como fazer", que, por sua vez, é embasado por conhecimentos fundamentais, que constituem o "saber". No entanto, a qualificação para a prática profissional, que constitui o "fazer", pressupõe que, em algum momento anterior à prática, ainda no âmbito da sua formação, o estudante deve demonstrar que domina as habilidades e competências necessárias. Isto constitui o "mostrar como faz", estrato da pirâmide sobre qual se assenta a prática.

As habilidades e competências referentes aos dois estratos basilares da pirâmide, o "saber" e o "saber como fazer", pertencem ao domínio cognitivo e, portanto, devem ser avaliadas com métodos apropriados à aferição de aquisição de conhecimentos. No entanto, diferem quanto à natureza do conhecimento, sendo o "saber" mais relacionado ao domínio "teórico" de fatos e mecanismos. Pode, portanto, ser avaliado com provas variadas, como os "testes de múltipla escolha" ou questões abertas de respostas diretas, dissertações e provas orais (Quadro 1). As mesmas estratégias podem ser usadas para avaliar o "saber como fazer", porém, o conhecimento neste nível já é mais do tipo "aplicado". Disto decorre que os exames propostos para este estrato devem ter como alvo o uso do conhecimento para a tomada de decisões e para a solução de problemas recomendando-se, portanto, que tenham contextualização clínica.

O estrato da pirâmide de Miller que corresponde ao "mostrar como faz" corresponde à avaliação de habilidades e competências clínicas, que deve ser feita ainda no âmbito da formação, ou na escola. Esta avaliação é usualmente feita com exames práticos envolvendo tarefas clínicas. Variam desde a observação direta do atendimento de pacientes reais pelo estudante até exames clínicos objetivos estruturados com o emprego de pacientes simulados, envolvendo tarefas diversificadas, aplicado simultaneamente a grande número de estudantes. (Quadro 2) O princípio subjacente a todos estes métodos de avaliação é a observação direta do examinando pelo examinador, enquanto este realiza tarefas clínicas que lhe foram solicitadas, ou que sejam pertinentes à situação clínica proposta.

Por fim, a avaliação do "fazer" corresponde àquela que deve ser feita no próprio ambiente de trabalho, onde a prática é exercida. Aplica-se ao estudante em final de curso, nos estágios profissionalizantes, onde se dá o treinamento para a prática do "fazer", com o estudante efetivamente "fazendo", ou
Quadro 1: Alguns métodos que podem ser empregados na avaliação das habilidades cognitivas, que corresponde aos estratos do "saber" e do "saber como fazer" da "Pirâmide de Miller"" (Figura 2).

PROVAS COM QUESTÕES ABERTAS

TESTES DE MÚLTIPLA ESCOLHA

ENSAIOS OU DISSERTAÇÕES

EXAMES ORAIS

Quadro 2: Alguns métodos que podem ser empregados na avaliação de habilidades e competências clínicas ${ }^{10}$, que corresponde ao estrato do "mostrar como faz" da "Pirâmide de Miller" (Figura 2).

EXAMES NÃO ESTRUTURADOS
prático-oral "observado"ou "não observado"
"caso longo"
"caso curto"
EXAMES SEMI-ESTRUTURADOS
O.S.L.E.R. (Objective Structured Long Examination
Record)
Mini-C.Ex. (mini- Clinical Exercise)
EXAMES ESTRUTURADOS
- O.S.C.E. (Objective Structured Clinical Examination)
- C.S.A. (Clinical Skills Assessment/Exercise)

seja exercitando a prática clínica, mas ainda sob supervisão. Esta porção apical da pirâmide corresponde também à avaliação do profissional já formado, no seu ambiente de trabalho, que também é conhecida como avaliação de desempenho. Existe uma variedade de métodos que podem ser aplicados à avaliação da prática profissional (Quadro 3). Estes métodos incluem os que se baseiam na análise do processo de trabalho, como o modo de preenchimento dos prontuários, as prescrições, os pedidos de exames e os encaminhamentos. Incluem também a análise de desfechos, ou seja, a verificação dos indicadores relativos às pessoas assistidas (morbidade, mortalidade, qualidade de vida). Uma forma bastante elabora- 
da e engenhosa de avaliar o trabalho do profissional ou estudante em estágio profissionalizante consiste nas visitas periódicas de pacientes padronizados incognito, em que um paciente simulado se apresenta ao profissional e após ser por ele abordado elabora para a instância responsável pela avaliação um relato do que foi feito, o que vai permitir que se avalie a adequação da abordagem. Inclui também o conjunto de métodos para a avaliação do profissional a chamada "avaliação em $360^{\circ}$ ", que consiste no cotejo da auto-avaliação feita pelo próprio avaliando com aquela que feita pelos seus colegas da mesma profissão ("pares"), por membros da equipe de trabalho de outras profissões, pelos pacientes ou usuários assistidos e pelos supervisores. Descrição mais detalhada destes métodos, bem como discussão crítica da sua utilidade é apresentada em excelente revisão da avaliação no campo da educação médica ${ }^{10}$, que se aplica inteiramente à todas as profissões da saúde.

Quadro 3: Métodos que podem ser empregados na avaliação do desempenho do estudante em treinamento ou do profissional já formado ${ }^{10}$, que corresponde ao estrato do "fazer" da "Pirâmide de Miller"9 (Figura 2).

\begin{tabular}{|c|}
\hline $\begin{array}{c}\text { ANÁLISE DO PROCESSO DE TRABALHO } \\
\text { prontuários, prescrições, pedidos de exames, } \\
\text { encaminhamentos }\end{array}$ \\
\hline $\begin{array}{l}\text { VISITAS PERIÓDICAS DE PACIENTES } \\
\text { PADRONIZADOS INCOGNITO }\end{array}$ \\
\hline $\begin{array}{c}\text { ANÁLISE DE DESFECHOS } \\
\text { indicadores reativos às pessoas assistidas } \\
\text { (qualidade de vida, morbidade, mortalidade) }\end{array}$ \\
\hline $\begin{array}{c}\text { AVALIAÇÃO " } 360^{\circ} " \\
\text { auto-avaliação, avaliação pelos pares, } \\
\text { membros da equipe de trabalho, supervisores } \\
\text { avaliação por pacientes ou usuários }\end{array}$ \\
\hline
\end{tabular}

\section{Atributos dos métodos de avaliação}

Quaisquer que sejam o foco da avaliação e o método empregado para tal, é importante que este tenha alguns atributos gerais, que podem ser considerados como determinantes de alta qualidade ${ }^{11,12}$ (Quadro 4).
Quadro 4: Atributos dos métodos e sistemas de avaliação ${ }^{11,12}$.

\begin{tabular}{c}
\hline Validade \\
\hline Confiabilidade (Fidedignidade) \\
\hline Viabilidade \\
\hline Aceitabilidade \\
\hline Impacto educacional \\
\hline Efeito catalisador \\
\hline
\end{tabular}

A validade é a propriedade de se avaliar exatamente aquilo que se pretende avaliar. Por exemplo, as habilidades cognitivas devem ser avaliadas por testes que avaliam a aquisição de conhecimentos, enquanto que as habilidades psicomotoras devem ser avaliadas com provas práticas. A tentativa de avaliar habilidades psicomotoras ou afetivas com perguntas, e não com a observação de comportamentos, vai resultar em uma situação em que será difícil demonstrar a validade do exame.

A confiabilidade ou fidedignidade é um atributo que diz respeito a qualidades como a precisão, acurácia, e reprodutibilidade. É determinada em grande parte pela atuação dos avaliadores e pelo controle das circunstâncias que podem afetar artificialmente $o$ desempenho do avaliando. Por exemplo, uma prova de conhecimentos preencherá mais facilmente os requisitos de confiabilidade se os critérios de correção das questões forem estabelecidos com antecedência e não se depender do juízo do momento do avaliador.

A viabilidade é uma característica relacionada à existência dos recursos necessários para realizar a avaliação. É particularmente importante quando há a necessidade de se programar provas práticas de maior extensão e sua aplicação a grande número de estudantes, o que exige contar com grupo maior de avaliadores, área física extensa ou com características peculiares, maior tempo para sua realização, entre outras condições. Nas ações de planejamento das avaliações, a viabilidade é um elemento crítico, pois algumas vezes, a busca de preenchimento dos requisitos de validade e fidedignidade impõe a execução de tarefas para as quais os recursos não são disponíveis, o que torna inviável aquilo que se pretendia executar. 
A aceitabilidade é a característica que permite à avaliação ser reconhecida como adequada e justa pelos participantes do processo avaliativo, como os estudantes e os avaliadores, bem como pelos representantes das instituições a quem a avaliação interessa. A falta de aceitabilidade impõe distorções que podem tornar inviável a execução da avaliação ou que afetam drasticamente os seus resultados, o que inevitavelmente prejudicará a qualidade da informação obtida.

No âmbito da escola, uma das características mais importantes dos métodos de avaliação é o seu impacto educacional, ou seja, o quanto irão repercutir sobre o próprio processo de ensino e aprendizado. Exemplos de avaliações com impacto educacional positivo são aquelas que já preveem a devolutiva ou feedback imediato aos avaliandos. Desta maneira, o bom desempenho pode ser reforçado e as eventuais deficiências podem ser corrigidas com presteza. Por outro lado, avaliações exclusivamente somativas, feitas somente ao final do curso, com foco unicamente no domínio cognitivo podem trazer impacto educacional negativo, uma vez que os estudantes vão se preocupar mais com o "passar" do que com o aprender.

Por fim, as avaliações podem ter um efeito catalítico nas transformações positivas pelas quais as pessoas e as instituições podem passar. Exemplo disto pode ser dado pela introdução de métodos ou sistemas inovadores de avaliação do estudante, que obriga a instituição prover recursos que também poderão ser utilizados na melhoria do ensino, como a capacitação dos professores em princípios e métodos de avaliação, o que por sua vez motiva e estimula os estudantes a se prepararem para ter um bom desempenho.

\section{Quando avaliar: a avaliação pontual e os sistemas de avaliação}

Em todo o sistema educacional brasileiro, é possível reconhecer uma situação comum: as avaliações constituem incumbência exclusiva do professor, são feitas predominantemente no final das disciplinas, estágios ou cursos e abrangem quase exclusivamente o domínio cognitivo. Assim, as avaliações tem um caráter mais pontual do que contínuo. Por outro lado, em vários países mais desenvolvidos, nota-se a tendência das instituições assumirem a responsabilidade pela avaliação, passando o professor a ser um partícipe do processo e a ter a importante função da avaliação formativa, como parte integral das atividades de ensino.

Entende-se aqui por instituição, a escola, a universidade, os hospitais e demais unidades do sistema de saúde, no caso do ensino superior nas profissões da saúde, bem como os órgãos reguladores, ligados à educação e às próprias profissões. Esta tendência enseja a construção de sistemas de avaliação, que podem contar com diferentes instrumentos, que vão prover informações das mais variadas naturezas, não só sobre o desempenho dos estudantes, mas também sobre as características dos processos de ensino e aprendizado, e que necessariamente tem caráter contínuo e natureza permanente.

A construção de sistemas de avaliação não é, porém, tarefa simples, exigindo não só investimentos vultosos em termos de recursos materiais, humanos e de tempo, como também mudança da mentalidade. Esse aspecto, em particular, implica em abrir mão do entendimento da avaliação educacional como instrumento de poder e de controle do comportamento do estudante, para passar a compreendê-la de forma diferente: no plano individual como recurso eficiente de apoio à aprendizagem e no plano coletivo como instrumento de gestão, visando o aperfeiçoamento dos processos educacionais e, em última instância, das próprias instituições.

\section{Recomendações para avaliações de boa qualidade}

Ao longo das últimas décadas do século XX, a área do conhecimento sobre a avaliação foi uma das que mais se desenvolveu no campo da educação nas profissões da saúde. Conceitos foram aprimorados, novos métodos foram desenvolvidos e técnicas tradicionais foram aperfeiçoadas. Mais do que isso, atingiu-se novo patamar no entendimento do poder e das possibilidades da avaliação no aprimoramento dos processos educacionais e também das instituições. No bojo destas transformações, um grupo de especialistas reunidos em um congresso internacional recente elaborou um conjunto de recomendações para garantir avaliações de boa qualidade ${ }^{12}$. São recomendações que constituem princípios, dos quais derivam aspectos práticos que envolvem todos os participantes dos processos avaliativos: estudantes, professores ou avaliadores, instituições ou escola, pacientes ou usuários da atenção à saúde, o sistemas de saúde e órgãos reguladores das profissões e das instituições. 


\section{Segundo estas recomendações, cabem:}

$\checkmark$ Aos estudantes:

- Conhecer os objetivos das avaliações;

- Ter garantias de que as avaliações a que se submetem preenchem requisitos de qualidade;

- Receber feedback que estimule o aprendizado em curso, do qual devem participar ativamente;

- Ter conhecimento, no devido tempo, sobre os critérios de atribuição de notas e de decisão sobre aprovação ou reprovação.

$\rightarrow$ Aos professores:

- Ensinar tendo como referência os objetivos instrucionais pré-estabelecidos;

- Elaborar as suas avaliações de modo a que maximizem o aprendizado dos estudantes;

- Utilizar os resultados das avaliações para aperfeiçoar o aprendizado futuro.

Ò̀s escolas:

- Prover capacitação e treinamento aos professores em avaliação educacional;

- Prover e alocar os diferentes recursos, inclusive o pessoal necessário, para garantir que as avaliações sejam bem feitas;

- Analisar a qualidade das avaliações, como parte dos processos de controle de qualidade do ensino;

- Garantir que as avaliações sejam consistentes e compatíveis com o currículo.

○ Aos pacientes:

- Participar como avaliadores, quando pertinente (ex.: avaliar habilidades de comunicação);

- Participar como instrutores, quando possam contribuir para o impacto educacional das avaliações;

- Contribuir para o aperfeiçoamento da compreensão das várias facetas do desempenho do avaliando;

- Receber garantias da boa qualidade das avaliações dos estudantes e profissionais em treinamento que os assistem.

○ Aos sistemas de saúde:

- Oferecer oportunidades para avaliações formativas continuadas;

- Facilitar o desenvolvimento de uma cultura de respostas estimulantes às avaliações formativas;

- Promover a pesquisa científica em avaliação no ambiente de trabalho.

$\rightarrow$ Aos órgãos reguladores:

- Levar em conta o impacto educacional das avaliações que fazem;

- Oferecer avaliações que garantam competência permanente;

- Reconhecer os efeitos catalíticos das avaliações na educação dos profissionais e nos próprios sistemas de saúde.

\section{Obstáculos e desafios para uma avaliação de maior qualidade}

A avaliação do processo ensino-aprendizagem na educação universitária enfrenta obstáculos para cumprir suas funções. O principal obstáculo se materializa na equivocada compreensão sobre as funções da avaliação. A ideia de avaliação remete á "prova" ou "exame", aquela situação escolar ameaçadora que classifica e estigmatiza o estudante. ${ }^{13}$ De fato, os es- tudantes chegam a Universidade carregando a herança da educação tradicional, mais especificamente, de um sistema de ensino cujos esforços se baseiam na memorização, voltado para produtos, e não para a aprendizagem. ${ }^{14}$

No cenário da educação universitária, a avaliação ganha contornos especiais, quando se trata da formação de profissionais da saúde. Avaliar a aquisição de conceitos e o desenvolvimento de habilidades e competências é tarefa complexa, sobretudo pelas ca- 
racterísticas de profissionais da saúde, que têm sido conceituados como "profissionais de desenvolvimento humano"*. O conceito abrange profissões que trabalham com pessoas em contato interpessoal direto, sendo a interação o próprio processo e parte fundamental do conteúdo da intervenção profissional. ${ }^{15}$

No contexto da formação de profissionais da saúde no Brasil, a avaliação carrega marcas do modelo tradicional de educação e é reflexo da organização curricular disciplinar (grade curricular) que separa e fragmenta a apresentação dos saberes aos estudantes em áreas, num formato centrado em conteúdos e sua transmissão, lógica que dificulta a integração entre teoria e prática. Em consequência disso, de maneira geral é possível afirmar que ainda prevalece o foco na avaliação cognitiva (conceitos), privilegiando a função somativa em detrimento da formativa. Isso se desdobra em ênfase excessiva à avaliação referenciada por disciplinas e uma certa negligência para com formação geral do estudante, desconsiderando os aspectos afetivos (atitudes) e psicomotores (procedimentais), tão fundamentais na formação de profissionais da saúde. A questão da aplicabilidade do conhecimento acaba por se perder em estratégias pontuais de avaliação, que não consideram diferentes estilos de aprendizagem e não apresentam caráter progressivo.

Possibilidades de resignificação da avaliação no contexto da educação universitária em saúde pressupõem que as estratégias de avaliação devem estar ajustadas à natureza do conhecimento ofertado na disciplina ou componente curricular. Isso requer um planejamento que integre os objetivos do projeto pedagógico do curso, o perfil final desejado, as metodologias de ensino e as estratégias e métodos de avaliação. Nesse sentido, alguns cuidados devem ser considerados para garantir um processo efetivo que resulte em aprendizado significativo:

- Avaliação progressiva: um conjunto de avaliações, em diferentes momentos do curso (disciplina ou componente curricular) em lugar da tradicional avaliação intermediária e final, ou só de uma avaliação final;

- Estratégias diferentes para avaliar diferentes domínios, estratégias diferentes num mesmo domínio para favorecer diferentes perfis de estudante (prova escrita dissertativa, prova escrita múltipla escolha; prova oral; trabalhos de análise e síntese; seminários; portfólio);

- Auto-avaliação;

- Avaliação por pares;

- Avaliação de habilidades clínicas por simulação ou estações.

Além disso, é importante que seja ofertada ao estudante a oportunidade de participar ativamente o processo, tendo ciência dos objetivos educacionais e das finalidades da avaliação, bem como das estratégias e critérios empregados na avaliação.

Em outras palavras, a superação desses obstáculos traz grandes desafios na imperiosa tarefa de aprimorar a avaliação do estudante nas profissões da saúde.

\section{Princlpals pontos de Interesse}

1. Avaliar, que significa "determinar o valor de alguma coisa," no campo educacional refere-se a qualquer atividade em que a evidência de aprendizagem do estudante, recolhida de forma planejada e sistemática, é utilizada para emitir um juízo sobre ela, visando alguma finalidade.

2. As principais finalidades da avaliação do estudante incluem reforçar o aprendizado (avaliação formativa) e subsidiar medidas de aperfeiçoamento do processo educativo (avaliação informativa), além de alicerçar decisões sobre aprovação, reprovação ou classificação (avaliação somativa).

3. O planejamento e a execução da avaliação demanda considerar os objetivos educacionais específicos de cada etapa da formação, de acordo com perfil final desejado (habilidades e competências), levando em conta os múltiplos domínios da aprendizagem (níveis cognitivo, psicomotor e afetivo).

4. A escolha dos métodos de avaliação do estudante deve se pautar no critério do melhor ajuste aos objetivos educacionais e à natureza das habilidades e competências cujo domínio se quer conhecer.

\footnotetext{
* O conceito abrange um conjunto de profissionais da saúde e bem estar (enfermeiros, terapeutas, psicólogos, nutricionistas); de trabalho social (assistente social, educador social, agentes familiares); de trabalho comunitário (técnicos de saúde comunitária, animadores culturais); de educação (professores, educadores, pedagogos). Os efeitos dos processos de desenvolvimento humano que resultam da intervenção desses profissionais assumem a forma de aprendizagem e desenvolvimento, modificação de comportamento, atitudes ou hábitos, adesão a normas ou modos de vida.
} 
5. O emprego dos métodos escolhidos deve considerar as suas características determinantes da qualidade da avaliação: validade, fidedignidade, viabilidade, aceitabilidade, impacto educacional e efeito catalítico.

6. A transformação de um cenário caracterizado por avaliações pontuais exclusivamente somativas, focadas predominantemente no domínio cognitivo, demanda considerar as perspectivas do estudante e capacitar os professores para a práticas integrativas e transformadoras, o que constitui atribuição das escolas, dos sistemas de saúde e dos órgãos reguladores da educação e das profissões.

\begin{abstract}
Student assessment plays a central role in health professions education. Assessing means to obtain information that will assist decision-making. It is therefore important that assessment planning and execution take into account its multiple functions, including reinforcing learning (formative assessment). Student assessment should focus not only on knowledge learning but also on the acquisition of psychomotor and affective skills, as well as documenting student progress and development. Assessment planning should be oriented by learning objectives previously defined for each educational step, according to desired outcomes in terms of skills and competences. The choice of methods for assessment should be guided by "what" is intended to be assessed, and also by "why" the assessment is being carried out. Characteristics of methods that determine a good assessment include validity, reliability, feasibility, acceptability, educational impact and catalytic effect. In the current Brazilian educational scenario concerning the health professions education assessments are focused predominantly on cognitive aspects aiming at pass/fail decision-making (summative assessment), with some disregard for considering skills and attitudes and for formative assessment. Transforming and improving assessment procedures involve considering student needs and standpoints and fostering faculty development, which is the responsibility of different stakeholders, such as schools, health systems and regulatory bodies.
\end{abstract}

Key-words: Assessment; Evaluation; Student; Health Professions Education.

\section{Referências Bibliográficas}

1. Dicionário on line de língua portuguesa Priberam, disponível em http://www.priberam.pt/dlpo/ (consultado em 05/03/2014).

2. Harlem, W.;Crick, RD A systemcatic review of the impact of summative assessment and tests on students' motivation for learning. London: EPPI-Centre, Social Science Research Unit, Institute of Education, University of London, 2002. Disponível em http://www.eppi.ioe.ac.uk, (consultado em 28/02/2014).

3. Sordi MRL. Alternativas propostas no campo da avaliação: por que não?. In: Castanho, S; Castanho, ME.(org) Temas e textos em metodologia do ensino superior. $6^{a}$. Ed. Campinas: Papirus, 2009.(Coleção Magistério: Formação e Trabalho Pedagógico).

4. Gardner J. Assesment and learning.2nd Edition.Thousand Oakes: SAGE, 2012.

5. Vasconcellos CS. Avaliação da Aprendizagem - Práticas de Mudança: por uma práxis transformadora. São Paulo: Libertad, 2003.

6. Bloom BSS; Englehart MD;Furst EJ; HILL WH; Klathwohl DR. Taxonomia de objetivos educacionais.Porto Alegre:Globo, 1976.

7. Anderson L, et al. A taxonomy for learning, teaching, and assessing: a revision of Bloom's Taxonomy of Educational Objectives. New York: Addison, Wesley Longman, 2001.
8. Pacheco JA. Processos e práticas de educação e formação: para uma análise da realidade portuguesa em contextos de globalização. Revista Portuguesa de Educação, 2009; 22: 105-43.

9. Miller GE. The assessment of clinical skills/competence/performance. Acad Med. 1990; 65: S63-S67.

10. Epstein RM. Assessment in Medical Education. N Engl J Med. 2007; 356:387-96.

11. Wass V, Van der Vleuten C, Shatzer J, Jones R. Assessment of clinical competence. Lancet. 2001; 357: 945-9.

12. Norcini J, Anderson B, Bollela V, Burch V, Costa MJ, Duvivier $\mathrm{R}$, et al. Criteria for good assessment: Consensus statement and recommendations from the Ottawa 2010 Conference. Med Teach. 2011; 33: 206-14.

13. Luckesi CCC. Avaliação da aprendizagem escolar. São Paulo: Cortez, 1995.

14. Pimenta SG; Anastasiou LGC. Docência no ensino superior. 4à . Ed. São Paulo: Cortez, 2010.

15. Formosinho J. Dilemas e tensões da atuação da universidade frente a formação de profissionais de desenvolvimento humano. In: Pimenta SG; Almeida MI (Org.) Pedagogia Universitária: caminhos para a formação de professores.São Paulo: Cortez, 2001. 